\title{
Transforming growth factor- $\beta$ signaling in head and neck squamous cell carcinoma: Insights into cellular responses (Review)
}

\author{
XIN PANG ${ }^{1,2}$, YA-LING TANG ${ }^{1,3}$ and XIN-HUA LIANG ${ }^{1,2}$ \\ ${ }^{1}$ State Key Laboratory of Oral Diseases; Departments of ${ }^{2}$ Oral and Maxillofacial Surgery, and ${ }^{3}$ Oral Pathology, \\ West China Hospital of Stomatology, Sichuan University, Chengdu, Sichuan 610041, P.R. China
}

Received April 12, 2017; Accepted June 27, 2018

DOI: $10.3892 / \mathrm{ol} .2018 .9319$

\begin{abstract}
Head and neck squamous cell carcinoma (HNSCC) arises in the oral cavity, salivary glands, larynx, pharynx, nasal cavity and paranasal sinuses, and is characterized by high morbidity and metastasis rates. Transforming growth factor- $\beta$ (TGF- $\beta$ ) is a homodimeric protein known to be a multifunctional regulator in target cells and to serve a pivotal role in numerous types of cancer, including HNSCC. The role of TGF- $\beta$ signaling in carcinogenesis can change from tumor-suppressing to tumor-promoting. In addition, TGF- $\beta$ induces epithelial-mesenchymal transition and restrains immune surveillance on malignant cells. In the present review, the effects of TGF- $\beta$ signaling at a cellular level were discussed, which includes the regulation of tumor cells, immune cells and other stromal cells, as well as the possible mechanisms underlying the conversion from a tumor suppressor to a tumor promoter in HNSCC. Further research is required to improve the understanding on how this network is involved in carcinogenesis, progression and metastases in HNSCC.
\end{abstract}

\section{Contents}

1. Introduction

2. Dual role of TGF- $\beta$ in HNSCC

3. Potential mechanisms underlying the conversion of TGF- $\beta$ from tumor suppressor to tumor promoter

4. Impact of TGF- $\beta$ on immune cells in HNSCC

5. Impact of TGF- $\beta$ on other cells in the TME

6. Conclusions

Correspondence to: Dr Xin-Hua Liang, Department of Oral and Maxillofacial Surgery, West China Hospital of Stomatology, Sichuan University, 14 Renminnan Road, Section 3, Chengdu, Sichuan 610041, P.R. China

E-mail: 1xh88866@scu.edu.cn

Dr Ya-Ling Tang, Department of Oral Pathology, West China Hospital of Stomatology, Sichuan University, 14 Renminnan Road, Section 3, Chengdu, Sichuan 610041, P.R. China

E-mail: tangyaling@scu.edu.cn

Key words: transforming growth factor- $\beta$, head and neck squamous cell carcinoma, cell cycle, immune evasion, metastasis, fibroblast

\section{Introduction}

Transforming growth factor- $\beta$ (TGF- $\beta$ ) signaling is widely known to serve an important role in the extracellular microenvironment and numerous cellular processes, including cell proliferation, differentiation, apoptosis and migration (1). Based on a significant amount of evidence in the literature, TGF- $\beta$ signaling is currently considered to have paradoxical impacts on cancer. TGF- $\beta$ functions as a tumor suppressor in normal epithelial cells or in the early stages of oncogenesis. However, as a tumor develops, TGF- $\beta$ becomes a potent tumor promoter in the epithelium at a later stage and even increases the production of TGF- $\beta$, supporting tumor progression and metastasis $(2,3)$.

TGF- $\beta$ is a regulatory cytokine that is secreted by tumor and stromal cells in the tumor microenvironment (TME). Members of the TGF- $\beta$ superfamily include TGF- $\beta$ s, bone morphogenic proteins, growth and differentiation factors, activins, inhibins and the anti-Müllerian hormone (4). Inactive TGF- $\beta$ cytokines, known as latent TGF- $\beta$ s, are located in the extracellular matrix. Upon activation, the ligand binds to TGF- $\beta$ receptor type II (T $\beta$ RII), which is constitutively activated, and then interacts with T $\beta$ RI (also termed activin receptor-like kinase), resulting in the formation of hetero-tetrameric complex and phosphorylation of T $\beta R I(5,6)$. The co-receptors (known as T $\beta$ RIII) may modulate the access of ligands to T $\beta R I$ and T $\beta R I I$, rather than being directly involved in the pathway (7). The hetero-tetrameric complex of active receptors initiates downstream signaling through canonical or non-canonical TGF- $\beta$ signaling. In the canonical signaling, active T $\beta$ RI recruits and phosphorylates receptor-regulated Smad (R-Smad) proteins, including Smad1-3, Smad5 and Smad8. Activated R-Smads associate with common-mediator Smad proteins (Smad4 in mammals) to form hetero-trimers, which subsequently translocate to the nucleus, bind to Smad-binding elements and regulate TGF- $\beta$-responsive genes in collaboration with cofactors, such as zinc-finger and forkhead (8-10). The inhibitory Smad proteins (including Smad6 and Smad7) compete with $\mathrm{R}$-Smads for binding to the receptors and recruit ubiquitin ligases to degrade T $\beta$ RI and R-Smads, thus modulating the intensity and duration of Smad-dependent signaling $(11,12)$. In the non-canonical TGF- $\beta$ signaling pathway, phosphorylated hetero-tetrameric receptors activate phosphoinositide 3-kinase/protein kinase B (PI3K/Akt), Ras homolog gene 
family member A and mitogen-activated protein kinase (MAPK) among others $(13,14)$.

Dysregulated TGF- $\beta$ signaling is common in several types of cancer, including head and neck squamous cell carcinoma (HNSCC) (15), and serves a crucial role in tumor prevention and progression. HNSCC accounts for $\sim 90 \%$ of head and neck cancer cases, and common risk factors include tobacco exposure, alcohol use, human papillomavirus infection and areca nut consumption. A series of therapies have been applied in the treatment of HNSCC, including surgery, radiotherapy, neoadjuvant chemotherapy and a combination of these methods (16). However, the 5-year survival rate of this disease has not evidently increased in last 30 years and remains at $\leq 50 \%$ (17-21). Accumulating evidence suggested that deregulation of TGF- $\beta$ signaling is of great importance in HNSCC and may be the result of defected TGF- $\beta$ signaling (22-24). Previous studies have demonstrated that the expression of Smad4 and Smad2 is frequently lost in HNSCC, while increased TGF- $\beta 1$ expression has been reported in the majority of these tumors. Mutations of T $\beta$ RII have been reported to occur in $21 \%$ of oral squamous cell carcinoma (OSCC) (25-27). In addition, T $\beta$ RII mRNA exhibited a $>50 \%$ loss in HNSCC and adjacent tissue samples as compared with the levels in normal tissue samples $(28,29)$. However, the exact role of TGF- $\beta$ in HNSCC is not completely understood. The present study reviews the current understanding on the TGF- $\beta$ signaling pathway and its impact on cells in the HNSCC microenvironment.

\section{Dual role of TGF- $\beta$ in HNSCC}

Tumor suppression. The tumor suppressive effect of TGF- $\beta$ was supported by several animal models with defected TGF- $\beta$ signaling. For example, T $\beta$ RI/phosphatase and tensin homolog (PTEN) knockout mice developed full-penetrance HNSCC while mice with PTEN deletion presented with hyperproliferation in the head and neck epithelium (30). Similarly, Smad4 deletion in head and neck epithelium also exhibited spontaneous HNSCC in mice (26). In normal epithelial cells, TGF- $\beta$ may maintain homeostasis through the regulation of proliferation and apoptosis. TGF- $\beta$ signaling arrests the cell cycle in phase G1, and mechanisms underlying normal cell growth inhibition include upregulation of cyclin-dependent kinase (CDK) inhibitors and downregulation of Myc expression (31). Smad3/Smad4 complexes interact with forkhead box $\mathrm{O}$ (FoxO) to increase the expression of CDK inhibitors, namely p15 and p21 (1,3,32). In the presence of co-repressors, Smad3/Smad4 complex also interact with regulatory elements of the Myc promoter, a cell cycle regulator gene $(33,34)$. As a consequence, the mRNA and protein expression of Myc are reduced. Smads induce apoptosis in epithelial cells through the activation of P53, Bcl-2-like protein 11 and death-associated protein kinase, and the repression of Akt. T $\beta$ RI also induces apoptosis in normal epithelial cells through TGF- $\beta$-activated kinase 1 (TAK1)-p38/c-Jun N-terminal kinase, independent of Smads (Fig. 1) (1,35-40). However, there is no direct evidence to support that the same molecular mechanisms are involved in HNSCC. Inhibitor of DNA-binding/differentiation (ID) proteins are known to negatively regulate cell differentiation by interfering with basic helix-loop-helix transcription factors. It has been reported that in keratinocytes TGF- $\beta$ upregulated the expression of cyclic AMP-dependent transcription factor-3, which served as a cofactor assisting the binding of Smad3/Smad4 complexes to the ID1 promoter; consequently, ID1 expression was downregulated and cell differentiation was promoted in vitro $(41,42)$.

Tumor promotion. Although TGF- $\beta$ signaling is widely known to mediate cell cycle arrest and enhance apoptosis in normal epithelium or in the early stage of tumor formation, it also induces epithelial cell overproliferation and inhibits apoptosis at a later stage of oncogenesis. For instance, Lu et al (27) demonstrated that tumor cells and epithelial cells from adjacent tissues expressed increased levels of TGF- $\beta 1$, as compared with those in epithelial cells from normal control human tissues. However, in transgenic mice, overexpression of TGF- $\beta 1$ was reported to result in the hyperproliferation of cells at the head and neck epithelium, and to enhance inflammation and angiogenesis (27). This suggested that TGF- $\beta 1$ promoted cell proliferation by the formation of an extracellular microenvironment in favor of tumor formation, even at early stage of carcinogenesis (Fig. 1) (27). Although, TGF- $\beta 1$ functions as a potent chemotactic molecule for leukocytes, it has been reported that inflammatory cytokines and growth factors secreted by infiltrated leukocytes may counteract the negative effects of TGF- $\beta 1$ on the cell cycle (27). In fact, loss of T $\beta$ RI or T $\beta$ RII partly subverts TGF- $\beta 1$-induced cell cycle arrest, and this effect along with the increased production of TGF- $\beta 1$ may result in its accumulation in the extracellular microenvironment. The loss of T $\beta$ RI or T $\beta$ RII has also been proven to lead to increased cell proliferation and inhibit the apoptosis of HNSCC cells, respectively $(29,30)$. Additionally, a previous study identified that improved proliferation and inhibited apoptosis due to decreased T $\beta$ RI levels were alternatively associated with the activation of the PI3K/Akt signaling pathway (43).

TGF- $\beta$ signaling disruptions are associated with poor prognosis partly due to the induction of epithelial-mesenchymal transition (EMT). EMT is a cellular process during which a cell with epithelial characteristics, such as cell polarity and cell-cell conjunction, translates to a cell with mesenchymal characteristics, such as motility (44). Decreased E-cadherin and increased vimentin levels are hallmarks of the EMT, while Snail and Twist are important factors negatively regulating E-cadherin (45). In OSCC, TGF- $\beta$ signaling has been implicated in EMT through Snail and upregulation of matrix metalloprotease 9 (MMP-9) levels $(46,47)$. Yu et al (48) demonstrated that TGF- $\beta 1$ expression in HNSCC was correlated with decreased E-cadherin level through the phosphorylation of $\mathrm{Smad} 2 / 3$ and subsequent involvement of Smad4, which bound to the Snail promoter (49). Independently of Smads, TGF- $\beta 1$ also regulates the Snail family proteins via the extracellular signal-regulated kinase (ERK)1/2 pathway in HNSCC (45). In addition, MMP-9 degrades the extracellular matrix components and basement membrane, and is regulated by TGF- $\beta 1$ through Smad2/3 and myosin light chain kinase in human HNSCC cell lines (Fig. 1) (50). Notably, Sun et al (46) demonstrated a reciprocal 


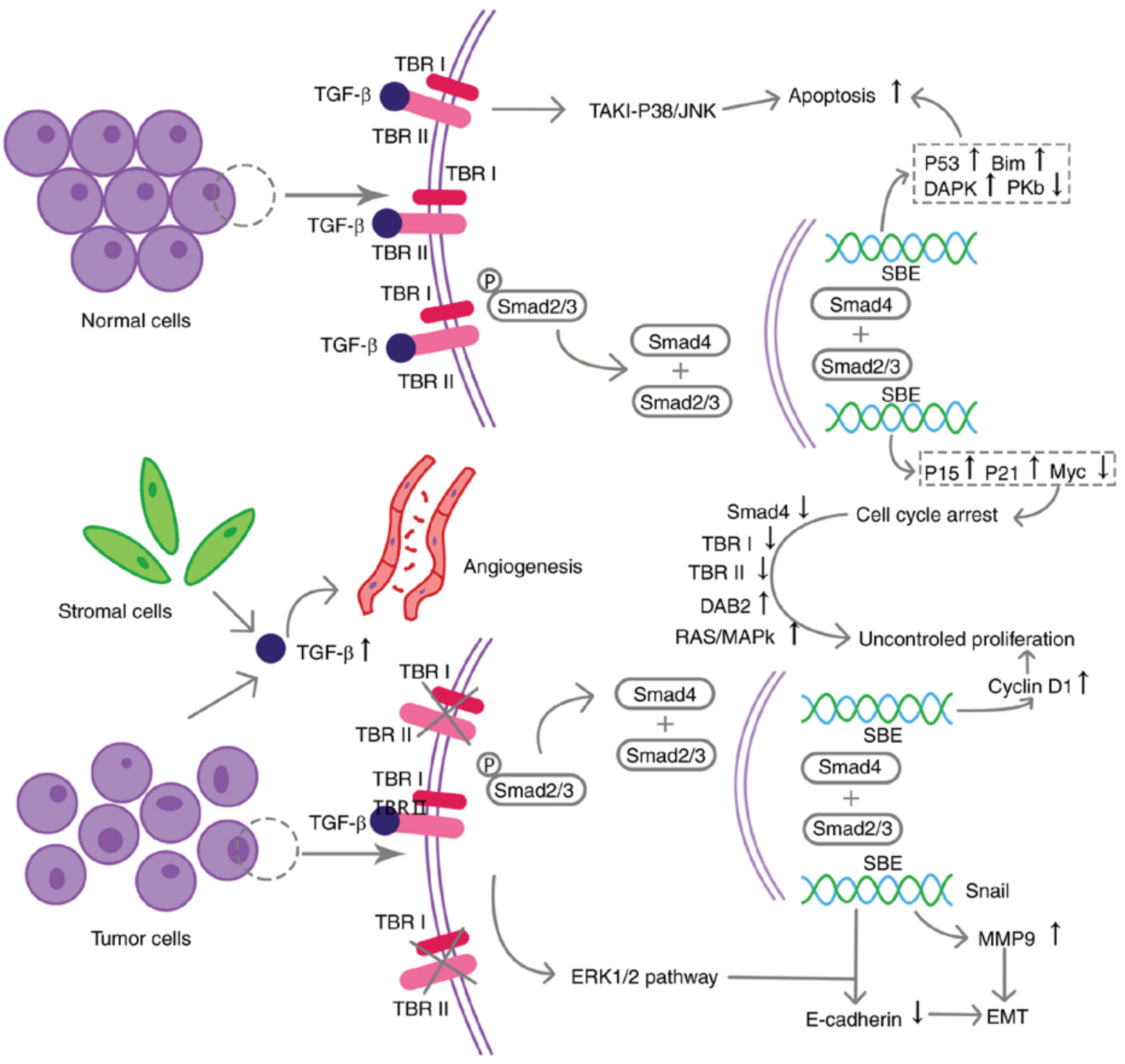

Figure 1. TGF- $\beta$ signaling maintains homeostasis between the proliferation and apoptosis of normal epithelial cells by Smads or other Smad-independent downstream pathways. Increased levels of TGF- $\beta$ contribute to angiogenesis, thus shaping a tumor microenvironment that allows uncontrolled epithelial proliferation. Increased DAB2 and activated Ras/MAPK signaling pathway, as well as defective TGF- $\beta$ signaling, which includes changes in Smad4, T $\beta R I$ and T $\beta$ RII, are in favor of uncontrolled proliferation of transformed cells. In addition, TGF- $\beta$ induces increased MMP-9 and decreased E-cadherin levels, which are hallmarks of EMT. Furthermore, tumor and stromal cells produce increased TGF- $\beta$ levels, forming a vicious cycle. TGF- $\beta$, transforming growth factor- $\beta$; DAB2, disabled homolog 2; MAPK, mitogen-activated protein kinase; T $\beta$ R, TGF- $\beta$ receptor; MMP-9, matrix metalloprotease 9; EMT, epithelial-mesenchymal transition; ERK, extracellular signal-regulated kinase; TAK1-p38/JNK, TGF- $\beta$-activated kinase 1-p38/c-Jun N-terminal kinase; SBE, Smad-binding element.

interaction between MMP-9 and Snail regulation. MMP-9 induced EMT partly through the expression of Snail, while Snail was involved in TGF- 31 -modulated MMP-9 expression by increasing Ets-1 (46). Another study indicated that TGF- $\beta 1$ promoted MMP-9 expression by Slug (Snail2) (51). Furthermore, TGF- $\beta 1$ may enhance EMT in cooperation with other growth factors in HNSCC. Compared with TGF- $\beta 1$ or epithelial growth factor (EGF) alone, long-term co-stimulation with TGF- $\beta 1$ and EGF in an OSCC cell culture model induced a phenotype transition, displaying upregulation of vimentin and downregulation of E-cadherin at the protein level, as well as markedly enhanced invasiveness (52). It was also reported that these observations may be associated with TGF- $\beta 1 /$ EGF causing extracellular matrix remodeling by a plasmin/MMP-10/MMP-1-dependent collagen remodeling axis (52).

\section{Potential mechanisms underlying the conversion of TGF- $\beta$ from tumor suppressor to tumor promoter}

The TGF- $\beta$ signaling pathway serves as a tumor suppressor at an early stage, whereas it serves as a tumor promoter in transformed epithelial cells at a later stage (31). Accordingly, the potential mechanisms underlying this conversion of the role of TGF- $\beta$ have been widely discussed due to their important effect on the balance of normal and transformed cells, and these mechanisms may serve as therapeutic targets in malignancies of an epithelial origin. Among the numerous possible mechanisms, investigation of mutations in the Smad-dependent pathway and disruption of the balance between this and other pathways may be of great importance.

In keratinocytes, the defected Smad4 pathway or alternative activated pathways (such as Erk) may abrogate growth 
inhibition and enable the pro-oncogenic effects of TGF- $\beta$. Defective Smads-dependent pathways overturn the effect of TGF- $\beta$ that induces cell cycle arrest and apoptosis and at the same time reciprocally interact with alternative pathways facilitating cancer invasion (53). Smad4 is a gatekeeper gene in HNSCC that directly controls cell proliferation, and decreased Smad4 expression has been verified to be correlated with irresponsiveness to TGF- $\beta$-induced growth inhibition (53). In addition, oncogenic Ras downregulates Smad4 by promoting the process of degradation (54); in return, low levels of Smad4 activate Ras-dependent ERK signaling, which is then involved in the progression to undifferentiated carcinoma in keratinocytes (55).

Disabled homolog 2 (DAB2), a putative tumor suppressor gene, suppresses Smad2 phosphorylation and activation. Hannigan et al (56) reported that, in SCC cell lines, the epigenetically downregulated DAB2 has been verified to negatively regulate Smad2 and its downstream pathway. By contrast, upon enhanced expression of DAB2, the cell lines presented growth prohibitive responses to TGF- $\beta$ again (56). Therefore, downregulated DAB2 contributes to converting TGF- $\beta$ into a tumor promoter, facilitating cell proliferation and anchorage-independent growth (Fig. 1).

Other mechanisms have also been suggested to be involved in this role conversion. For instance, T $\beta$ RII is reportedly significantly decreased in primary HNSCC (57), resulting in TGF- $\beta 1$ accumulation in the TME. In place of suppressing overproliferation in epithelial cells, excessive TGF- $\beta 1$ levels may directly affect the tumor stroma, inducing effects such as promotion of angiogenesis, myofibroblast formation and exertion of a chemotactic effect on neutrophils and macrophages (29). Notably, TRRII mutation in the epithelium is also a classic mechanism that subverts growth arrest and contributes to a tumor-friendly microenvironment by increasing inflammation and angiogenesis (Fig. 1). Additionally, the suppressive effect of Smad7 on the canonical TGF- $\beta$ signaling pathway is greater than that on non-canonical pathways involving TAK1 signaling, such as TAK1-NF- $\mathrm{BB}$ signaling, which favors malignant progression. Freudlsperger et al (58) demonstrated that, in HNSCC cell lines, the relatively preferential suppression by Smad7 on Smad-dependent growth inhibition may favor the conversion. The development of cancer cell tolerance to the TGF- $\beta$-mediated growth inhibition is currently an important focus of carcinogenesis, progression and treatment research; however, the intricate conversion mechanism remains unclear to date.

\section{Impact of TGF- $\beta$ on immune cells in HNSCC}

Immune surveillance. The concept of tumor immune surveillance was initially described in 1967 by Burnet (59). This refers to an organism discerning and eliminating cancer cells via the innate and adaptive immune system. At the same time, cancer cells are able to evade discernment and attack from the immune system, thus promoting tumor progression. Over the last 50 years, TGF- $\beta$ has been demonstrated to abrogate tumor-suppressing immune cell functions and to support tumor-promoting functions in certain types of cancer $(23,24,60)$. This section outlines how TGF- $\beta$ signaling promotes tumor progression in HNSCC by affecting several types of immune cells.
Innate immune system. Dendritic cells (DCs), first identified by Steinman in 1973 (61), are the most efficient antigen-presenting cells $(61,62)$. Researchers have identified DC inactivation in HNSCC bearing hosts (63). Exogenous TGF- $\beta$ has been demonstrated to hamper DC maturation by compromising the expression levels of major histocompatibility complex class II and costimulatory molecules (64). In addition, TGF- $\beta$ immobilizes DCs in order to prevent the migration of DCs and tumor antigens to lymph nodes $(17,65)$. Upon exposure to TGF- $\beta$, DCs facilitate immune tolerance and the differentiation of $\mathrm{CD}^{+} \mathrm{T}$ cells to $\mathrm{T}$ regulatory cells (Tregs) in the TME of HNSCC (66). These results suggested that TGF- $\beta$ induced DC dysfunction via regulating the maturation and mobility of DCs in peripheral organs.

Previous studies have indicated that tumor-associated macrophages are mainly of the M2 phenotype and are positively correlated with the histopathological grades of HNSCC bearing hosts (67-69). Exposure to enhanced expression of TGF- $\beta$ results in an M2 macrophage phenotype, which typically expressed CD206 (70). Mechanisms of TGF- $\beta$ inducing M2 include the negative regulation of Toll-like receptor (TLR) signaling that causes induction of anti-tumor cytokines, such as tumor necrosis factor (TNF)- $\alpha$, interleukin (IL)-12 and interferon (IFN)- $\gamma$, in order to participate in macrophage responses $(71,72)$. Furthermore, Standiford et al (73) demonstrated that activated TGF- $\beta$ signaling is required in IL receptor-associated kinase induction, which is a critically negative regulator of TLR signaling. Besides participating in macrophages polarization, TGF- $\beta$ recruits macrophages to the TME, where they further produce TGF- $\beta$ and thus a vicious cycle is formed (60).

Natural killer (NK) cells are frequently incompetent in HNSCC $(74,75)$, and have been demonstrated to be suppressed by TGF- $\beta$, partly due to the stable expression of T $\beta$ RII on NK cells $(31,76)$. TGF- $\beta$ binds to T $\beta$ RII and then activates downstream components, resulting in the transcriptional repression of NK group 2 member D (NKG2D) tumor cell recognition receptors, in turn suppressing the cytotoxic effects of NK cells (76,77). Similarly, Klöss et al (78) reported that enhanced TGF- $\beta 1$ plasma levels were correlated with a decreased NKG2D-dependent cytotoxic ability in relapsed HNSCC patients. Furthermore, Ghiringhelli et al (79) indicated that membrane-bound TGF- $\beta$ expressed on Tregs negatively regulated NKG2D and the type I transmembrane protein NKp30 on NK cells, thus suppressing NK cell functions through Treg-NK cell interaction.

Myeloid-derived suppressor cells (MDSCs), first detected in cancer patients in 1984 (80), consist of a heterogeneous population of immature myeloid cells, including the precursors of DCs and macrophages. One of the most notable characteristics of MDSCs is that they suppress the activity of T cells $(81,82)$. Previous studies have reported the presence of MDSCs in the peripheral blood of HNSCC patients, and that high infiltration of MDSCs promoted an immune-suppressive TME (83-85). Bian et al (30) demonstrated that decreased TGF- $\beta$ signaling upregulated C-X-C motif chemokine ligand (CXCL)1, CXCL5, prostaglandin-endoperoxide synthase 2 and CXC receptor 3, contributing to the recruitment of MDSCs in an HNSCC model in T $\beta \mathrm{RI} /$ phosphatase and tensin homolog (PTEN) 2cKO mice. However, further research is 
required to support whether the recruitment of MDSCs in an HNSCC model is associated with a TGF- $\beta$ signaling defect alone, or simultaneous TGF- $\beta$ signaling defect and PTEN loss.

Adaptive immune system. T lymphocytes can be classified into four subtypes, including cytotoxic $\mathrm{T}$, helper $\mathrm{T}(\mathrm{Th})$, regulatory $\mathrm{T}$ (Treg) and memory $\mathrm{T}(\mathrm{Tm})$ cells. With the exception of Tm cells, all these subtypes have been verified to serve an important role in tumor escape from immune surveillance (86). Similarly to epithelial cells, TGF- $\beta$ induces primary $\mathrm{T}$ lymphocyte growth inhibition in G1 phase by downregulating CDK4 (87). In addition, the trigger of the conversion of local primary $\mathrm{T}$ cells to Treg or Th cells in mice is partly associated with the transcription factor FoxP3 and retinoic acid receptor-related orphan receptor $\gamma \mathrm{t}$, respectively, whose transcription activity can be modulated by TGF- $\beta(88,89)$.

Treg cells, a subtype of $\mathrm{CD}^{+} \mathrm{T}$ lymphocytes, suppress tumor immune reaction and contribute to the immune tolerance to tumor antigens. Research has verified an enrichment of Treg cells in the blood of HNSCC patients $(90,91)$, and these cells are recruited and activated by TGF- $\beta 1$ (92). Among them, the Treg type 1 cells produce TGF- $\beta 1$ and IL-10, rather than having direct contact with responder cells to induce inhibition, and thus favor local immune suppression $(92,93)$. TGF- $\beta$ skews $\mathrm{CD}^{+} \mathrm{T}$ cells differentiating away from antitumor effector Th1 and towards the Th17 phenotype. Li et al (94) suggested that the proportion of Th17 cells in the peripheral blood increased with cancer progression and metastasis. This proportion was higher in the blood of HNSCC patients, with evidently enhanced levels observed in patients with advanced tumors and/or lymph node metastasis. Furthermore, Th17 cells are characterized by the production of IL-17, whose secretion is associated with TGF- $\beta$ in HNSCC patients $(94,95)$. IL-17 acts to induce tumor cell proliferation and, notably, enhances angiogenesis in immune-deficient hosts, contributing to a tumor friendly microenvironment $(2,17)$. In a study by Laad et al (96), low $\mathrm{CD}^{+}$cytotoxic T lymphocytes (CTL) frequency was reported in the peripheral blood and tumor tissues of oral cancer patients. CTLs are often inactivated, while the expression levels of their effector products for cytolysis, namely IFN- $\gamma$, granzyme A, granzyme B, perforin and Fas ligand, are repressed by TGF- $\beta$ (65). Taken together, TGF- $\beta$ and its downstream signaling are able to interfere with $\mathrm{CD}^{+}{ }^{+}$and $\mathrm{CD}^{+} \mathrm{T}$ cell differentiation and effector functions.

\section{Impact of TGF- $\beta$ on other cells in the TME}

Besides tumor and immune cells, stromal cells are another important component of the TME. HNSCC has a relatively low survival rate, which may be the consequence of the complex symbiotic association among tumor cells, surrounding stromal cells (including fibroblasts) and the neoplastic extracellular matrix (97). TGF- $\beta$ interferes with these cells in a paracrine or autocrine manner, leading to increased inflammation and angiogenesis, and consequently to tumorigenesis and tumor invasiveness, as reported in a study by Lu et al (27). A full discussion of how TGF- $\beta$ signaling regulates stromal cells in the TME is beyond the scope of the present review, and the attention of this section will focus on the effects of TGF- $\beta$ signaling on cancer-associated fibroblasts (CAFs).
CAFs have been proven to be critical in tumor growth and metastasis by Wheeler et al (98) in an orthotopic floor-of-mouth tumor model. CAFs are characterized by the expression of integrin $\alpha 6$, which is closely correlated with cell adhesion and worsened patient prognosis in OSCC (99). Additionally, these fibroblasts may be involved in the resistance of tumor cells to cetuximab treatment in HNSCC. Cytokines, such as TGF- $\beta 1$, TNF, CXCL8 and hepatocyte growth factor, secreted by CAFs in patients with HNSCC have stronger immune-suppressive effects on T cells in comparison with those secreted by normal fibroblasts (100). The CAFs secret TGF- $\beta 1$ in the TME, and in turn, TGF- $\beta 1$ in the TME is considered to promote CAF proliferation, as well as the secretion of growth factors and proteases that participate in cancer invasion (101). Loss of TGF- $\beta$ signaling increases the expression of CXCL1, CXCL5, CXCL12 and TGF- $\beta 1$ in fibroblasts, as evidenced by $\mathrm{Xu}$ et al (102). Furthermore, in OSCC patients, the mRNA and protein levels of T $\beta$ RII and T $\beta$ RIII are markedly lower in CAFs as compared with those in normal fibroblasts (103). Another study revealed that disrupted TGF- $\beta$ signaling in fibroblasts led to increased stromal cells and invasive squamous cell carcinoma of the forestomach in mice with conditional inactivation of T $\beta$ RII (104).

\section{Conclusions}

HNSCC is the sixth most frequent type of cancer worldwide (105), and the high recurrence and metastasis rates suggest an urgent need to elaborate the molecular mechanisms involved in the processes of carcinogenesis, cancer progression and metastasis. TGF- $\beta$ is a pleiotropic cytokine that regulates the cell cycle progression, differentiation and apoptosis of tumor cells, immune cells and other stromal cells in the TME. As the mechanisms underlying the involvement of the TGF- $\beta$ signaling pathway in HNSCC are investigated, the dual role of TGF- $\beta$ and its conversion between tumor suppressor and promoter have received increasing interest. Intact TGF- $\beta$ signaling has been reported to balance the proliferation and apoptosis in the epithelium. While exposed to defective TGF- $\beta$ signaling, tumor cells acquire resistance to TGF- $\beta$-induced growth inhibition and undergo EMT. Immune cells and CAFs react on TGF- $\beta$ to form a TME that promotes cancer invasion and metastasis, and to help tumor cells escape from immune surveillance. Although TGF- $\beta$ signaling pathway has been widely studied in various types of cancer for several decades, the fundamental mechanisms underlying this conversion at a cellular level in HNSCC need to be further investigated in the future. Additionally, in order to identify novel therapeutic targets, further research in the context of HNSCC patients and/or cell lines is required to thoroughly explore internal mechanisms and external manifestations.

\section{Acknowledgements}

Not applicable.

\section{Funding}

The present study was supported by National Natural Science Foundation of China grants (grant nos. 81672672, 81772891, 
81572650 and 81621062 ), and by National Program on Key Research Project of China (grant no. 2016YFC0902700).

\section{Availability of data and materials}

Not applicable.

\section{Authors' contributions}

$\mathrm{XP}$ was mainly responsible for the manuscript writing. YLT and XHL provided suggestions on the ideas and performed the final corrections.

\section{Ethics approval and consent to participate}

Not applicable.

\section{Patient consent for publication}

Not applicable.

\section{Competing interests}

The authors declare that they have no competing interests.

\section{References}

1. Meulmeester E and Ten Dijke P: The dynamic roles of TGF- $\beta$ in cancer. J Pathol 223: 205-218, 2011.

2. Pickup M, Novitskiy S and Moses HL: The roles of TGF $\beta$ in the tumour microenvironment. Nat Rev Cancer 13: 788-799, 2013.

3. Drabsch Y and ten Dijke P: TGF- $\beta$ signalling and its role in cancer progression and metastasis. Cancer Metastasis Rev 31: 553-568, 2012.

4. Wakefield LM and Hill CS: Beyond TGF $\beta$ : Roles of other TGF $\beta$ superfamily members in cancer. Nat Rev Cancer 13: 328-341, 2013

5. Cantelli G, Crosas-Molist E, Georgouli M and Sanz-Moreno V: TGF $\beta$-induced transcription in cancer. Semin Cancer Biol 42: 60-69, 2017.

6. López-Casillas F, Wrana JL and Massagué J: Betaglycan presents ligand to the TGF beta signaling receptor. Cell 73: 1435-1444, 1993.

7. Gatza CE, Sun YO and Blobe GC: Roles for the type III TGF- $\beta$ receptor in human cancer. Cell Signal 22: 1163-1174, 2010.

8. Schmierer B and Hill CS: Kinetic analysis of Smad nucleocytoplasmic shuttling reveals a mechanism for transforming growth factor beta-dependent nuclear accumulation of Smads. Mol Cell Biol 25: 9845-9858, 2005.

9. Nakao A, Imamura T, Souchelnytskyi S, Kawabata M, Ishisaki A, Oeda E, Tamaki K, Hanai J, Heldin CH, Miyazono K and ten Dijke P: TGF-beta receptor-mediated signalling through Smad2, Smad3 and Smad4. EMBO J 16: 5353-5362, 1997.

10. Koinuma D, Tsutsumi S, Kamimura N, Imamura T, Aburatani H and Miyazono K: Promoter-wide analysis of Smad4 binding sites in human epithelial cells. Cancer Sci 100: 2133-2142, 2009.

11. Itoh S and ten Dijke P: Negative regulation of TGF-beta receptor/Smad signal transduction. Curr Opin Cell Biol 19: 176-184, 2007.

12. Kavsak P, Rasmussen RK, Causing CG, Bonni S, Zhu H, Thomsen GH and Wrana JL: Smad7 binds to Smurf2 to form an E3 ubiquitin ligase that targets the TGF beta receptor for degradation. Mol Cell 6: 1365-1375, 2000.

13. Ohkawara B, Shirakabe K, Hyodo-Miura J, Matsuo R, Ueno N, Matsumoto K and Shibuya H: Role of the TAK1-NLK-STAT3 pathway in TGF-beta-mediated mesoderm induction. Genes Dev 18: 381-386, 2004.

14. Massagué $\mathrm{J}$ and Gomis RR: The logic of TGF $\beta$ signaling. FEBS Lett 580: 2811-2820, 2006.

15. Malkoski SP and Wang XJ: Two sides of the story? Smad4 loss in pancreatic cancer versus head-and-neck cancer. FEBS Lett 586: 1984-1992, 2012.
16. Krstevska V: Evolution of treatment and high-risk features in resectable locally advanced Head and Neck squamous cell carcinoma with special reference to extracapsular extension of nodal disease. J BUON 20: 943-953, 2015

17. Moutsopoulos NM, Wen J and Wahl SM: TGF-beta and tumors-an ill-fated alliance. Curr Opin Immunol 20: 234-240, 2008.

18. Parkin DM, Bray F, Ferlay J and Pisani P: Global cancer statistics, 2002. CA Cancer J Clin 55: 74-108, 2005.

19. Edwards BK, Ward E, Kohler BA, Eheman C, Zauber AG, Anderson RN, Jemal A, Schymura MJ, Lansdorp-Vogelaar I, Seeff LC, et al: Annual report to the nation on the status of cancer, 1975-2006, featuring colorectal cancer trends and impact of interventions (risk factors, screening, and treatment) to reduce future rates. Cancer 116: 544-573, 2010.

20. Grsic K, Opacic IL, Sitic S, Milkovic PM, Suton P and Sarcevic B: The prognostic significance of estrogen receptor $\beta$ in head and neck squamous cell carcinoma. Oncol Lett 12: 3861-3865, 2016.

21. Bae WJ, Lee SH, Rho YS, Koo BS and Lim YC: Transforming growth factor $\beta 1$ enhances stemness of head and neck squamous cell carcinoma cells through activation of Wnt signaling. Oncol Lett 12: 5315-5320, 2016

22. Honjo Y, Bian Y, Kawakam K, Molinolo A, Longenecker G, Boppana R, Larsson J, Karlsson S, Gutkind JS, Puri RK and Kulkarni AB: TGF- $\beta$ receptor I conditional knockout mice develop spontaneous squamous cell carcinoma. Cell Cycle 6: 1360-1366, 2007.

23. Connolly EC and Akhurst RJ: The complexities of TGF- $\beta$ action during mammary and squamous cell carcinogenesis. Curr Pharm Biotechnol 12: 2138-2149, 2011.

24. Pring M, Prime S, Parkinson EK and Paterson I: Dysregulated TGF-beta1-induced Smad signalling occurs as a result of defects in multiple components of the TGF-beta signalling pathway in human head and neck carcinoma cell lines. Int J Oncol 28: 1279-1285, 2006.

25. Agrawal N, Frederick MJ, Pickering CR, Bettegowda C, Chang K, Li RJ, Fakhry C, Xie TX, Zhang J, Wang J, et al: Exome sequencing of head and neck squamous cell carcinoma reveals inactivating mutations in NOTCH1. Science 333: 1154-1157, 2011.

26. Bornstein S, White R, Malkoski S, Oka M, Han G, Cleaver T, Reh D, Andersen P, Gross N, Olson S, et al: Smad4 loss in mice causes spontaneous head and neck cancer with increased genomic instability and inflammation. J Clin Invest 119: 3408-3419, 2009.

27. Lu SL, Reh D, Li AG, Woods J, Corless CL, Kulesz-Martin M and Wang XJ: Overexpression of transforming growth factor $\beta 1$ in head and neck epithelia results in inflammation, angiogenesis, and epithelial hyperproliferation. Cancer Res 64: 4405-4410, 2004.

28. Snijders AM, Schmidt BL, Fridlyand J, Dekker N, Pinkel D, Jordan RC and Albertson DG: Rare amplicons implicate frequent deregulation of cell fate specification pathways in oral squamous cell carcinoma. Oncogene 24: 4232-4242, 2005.

29. Lu SL, Herrington H, Reh D, Weber S, Bornstein S, Wang D, Li AG, Tang CF, Siddiqui Y, Nord J, et al: Loss of transforming growth factor-beta type II receptor promotes metastatic head-and-neck squamous cell carcinoma. Genes Dev 20: 1331-1342, 2006

30. Bian Y, Hall B, Sun ZJ, Molinolo A, Chen W, Gutkind JS Waes CV and Kulkarni AB: Loss of TGF- $\beta$ signaling and PTEN promotes head and neck squamous cell carcinoma through cellular senescence evasion and cancer-related inflammation. Oncogene 31: 3322-3332, 2012.

31. White RA, Malkoski SP and Wang XJ: TGF $\beta$ signaling in head and neck squamous cell carcinoma. Oncogene 29: 5437-5446, 2010.

32. Alexandrow MG and Moses $\mathrm{H}$ : Transforming growth factor $\mathrm{b}$ and cell cycle regulation. Cancer Res 55: 1452-1457, 1995.

33. Kim T, Cui R, Jeon YJ, Fadda P, Alder H and Croce CM: MYC-repressed long noncoding RNAs antagonize MYC-induced cell proliferation and cell cycle progression. Oncotarget 6: 18780-18789, 2015.

34. Chen CR, Kang Y, Siegel PM and Massagué J: E2F4/5 and p107 as Smad cofactors linking the TGFbeta receptor to c-myc repression. Cell 110: 19-32, 2002.

35. Massague J: TGFbeta in Cancer. Cell 134: 215-230, 2008

36. Pardali K and Moustakas A: Actions of TGF-beta as tumor suppressor and pro-metastatic factor in human cancer. Biochim Biophys Acta 1775: 21-62, 2007. 
37. Sorrentino A, Thakur N, Grimsby S, Marcusson A, von Bulow V, Schuster N, Zhang S, Heldin CH and Landström M The type I TGF-beta receptor engages TRAF6 to activate TAK1 in a receptor kinase-independent manner. Nat Cell Biol 10: 1199-1207, 2008.

38. Yamashita M, Fatyol K, Jin C, Wang X, Liu Z and Zhang YE: TRAF6 mediates smad-independent activation of JNK and p38 by TGF-beta. Mol Cell 31: 918-924, 2008.

39. Zhang S, Ekman M, Thakur N, Bu S, Davoodpour P, Grimsby S, Tagami S, Heldin CH and Landström M: TGFbeta1-induced activation of ATM and p53 mediates apoptosis in a Smad7-dependent manner. Cell Cycle 5: 2787-2795, 2006.

40. Jang CW, Chen CH, Chen CC, Chen JY, Su YH and Chen RH: TGF-beta induces apoptosis through Smad-mediated expression of DAP-kinase. Nat Cell Biol 4: 51-58, 2001.

41. Korchynskyi O and ten Dijke P: Identification and functional characterization of distinct critically important bone morphogenetic protein-specific response elements in the Id1 promoter. J Biol Chem 277: 4883-4891, 2002.

42. Kang Y, Chen CR and Massagué J: A self-enabling TGFbeta response coupled to stress signaling: Smad engages stress response factor ATF3 for Id1 repression in epithelial cells. Mo Cell 11: 915-926, 2003.

43. Bian Y, Terse A, Du J, Hall B, Molinolo A, Zhang P, Chen W, Flanders KC, Gutkind JS, Wakefield LM and Kulkarni AB: Progressive tumor formation in mice with conditional deletion of TGF-beta signaling in head and neck epithelia is associated with activation of the PI3K/Akt pathway. Cancer Res 69: 5918-5926, 2009.

44. Liu S, Ye D, Guo W, Yu W, He Y, Hu J, Wang Y, Zhang L, Liao Y, Song H, et al: G9a is essential for EMT-mediated metastasis and maintenance of cancer stem cell-like characters in head and neck squamous cell carcinoma. Oncotarget 6 : 6887-6901, 2015.

45. Smith A, Teknos TN and Pan Q: Epithelial to mesenchymal transition in head and neck squamous cell carcinoma. Oral Oncol 49: 287-292, 2013.

46. Sun L, Diamond ME, Ottaviano AJ,Joseph MJ, Ananthanarayan V and Munshi HG: Transforming growth factor-beta 1 promotes matrix metalloproteinase-9-mediated oral cancer invasion through snail expression. Mol Cancer Res 6: 10-20, 2008.

47. Qiao B, Johnson NW and Gao J: Epithelial-mesenchymal transition in oral squamous cell carcinoma triggered by transforming growth factor-betal is Snail family-dependent and correlates with matrix metalloproteinase-2 and -9 expressions. Int J Oncol 37: 663-668, 2010

48. Yu C, Liu Y, Huang D, Dai Y, Cai G, Sun J, Xu T, Tian Y and Zhang X: TGF- $\beta 1$ mediates epithelial to mesenchymal transition via the TGF- $\beta /$ Smad pathway in squamous cell carcinoma of the head and neck. Oncol Rep 25: 1581, 2011.

49. Hoot KE,Lighthall J, Han G, Lu SL, Li A, Ju W, Kulesz-Martin M, Bottinger E and Wang XJ: Keratinocyte-specific Smad2 ablation results in increased epithelial-mesenchymal transition during skin cancer formation and progression. J Clin Invest 118 2722-2732, 2008

50. Sinpitaksakul SN, Pimkhaokham A, Sanchavanakit N and Pavasant P: TGF-betal induced MMP-9 expression in HNSCC cell lines via Smad/MLCK pathway. Biochem Biophys Res Commun 371: 713-718, 2008

51. Joseph MJ, Dangi-Garimella S, Shields MA, Diamond ME, Sun L, Koblinski JE and Munshi HG: Slug is a downstream mediator of transforming growth factor-betal-induced matrix metalloproteinase-9 expression and invasion of oral cancer cells J Cell Biochem 108: 726-736, 2009.

52. Richter P, Umbreit C, Franz M, Berndt A, Grimm S, Uecker A, Böhmer FD, Kosmehl $\mathrm{H}$ and Berndt A: EGF/TGF $\beta 1$ co-stimulation of oral squamous cell carcinoma cells causes an epithelial-mesenchymal transition cell phenotype expressing laminin 332. J Oral Pathol Med 40: 46-54, 2011.

53. Korc M: Smad4: Gatekeeper gene in head and neck squamous cell carcinoma. J Clin Invest 119: 3208-3211, 2009.

54. Saha D, Datta PK and Beauchamp RD: Oncogenic ras represses transforming growth factor-beta/Smad signaling by degrading tumor suppressor Smad4. J Biol Chem 276: 29531-29537, 2001

55. Iglesias M, Frontelo P, Gamallo C and Quintanilla M: Blockade of Smad4 in transformed keratinocytes containing a Ras oncogene leads to hyperactivation of the Ras-dependent Erk signalling pathway associated with progression to undifferentiated carcinomas. Oncogene 19: 4134-4145, 2000.
56. Hannigan A, Smith P, Kalna G, Lo Nigro C, Orange C, O'Brien DI, Shah R, Syed N, Spender LC, Herrera B, et al: Epigenetic downregulation of human disabled homolog 2 switches TGF-beta from a tumor suppressor to a tumor promoter. J Cli Invest 120: 2842-2857, 2010.

57. Wang D, Song H, Evans JA, Lang JC, Schuller DE and Weghorst CM: Mutation and downregulation of the transforming growth factor beta type II receptor gene in primary squamous cell carcinomas of the head and neck. Carcinogenesis 18: 2285-2290, 1997

58. Freudlsperger C, Bian Y, Contag Wise S, Burnett J, Coupar J, Yang X, Chen Z and Van Waes C: TGF- $\beta$ and NF- $\kappa B$ signal pathway cross-talk is mediated through TAK1 and SMAD7 in a subset of head and neck cancers. Oncogene 32: 1549-1559, 2013.

59. Burnet FM: Immunological aspects of malignant disease. Lancet 1: 1171-1174, 1967.

60. Yang L: TGFbeta and cancer metastasis: An inflammation link. Cancer Metastasis Rev 29: 263-271, 2010

61. Steinman RM and Cohn ZA: Identification of a novel cell type in peripheral lymphoid organs of mice. I. Morphology, quantitation, tissue distribution. J Exp Med 137: 1142-1162, 1973.

62. Banchereau J and Steinman RM: Dendritic cells and the control of immunity. Nature 392: 245-252, 1998.

63. Duray A, Demoulin S, Hubert P, Delvenne P and Saussez S: Immune suppression in head and neck cancers: A review. Clin Dev Immunol 2010: 701657, 2010.

64. Wrzesinski SH, Wan YY and Flavell RA: Transforming growth factor-beta and the immune response: implications for anticancer therapy. Clin Cancer Res 13: 5262-5270, 2007.

65. Khazaie $\mathrm{K}$ and von Boehmer $\mathrm{H}$ : The impact of $\mathrm{CD} 4+\mathrm{CD} 25+$ Treg on tumor specific CD8+ T cell cytotoxicity and cancer. Semin Cancer Biol 16: 124-136, 2006.

66. Curry JM, Sprandio J, Cognetti D, Luginbuhl A, Bar-ad V, Pribitkin E and Tuluc M: Tumor microenvironment in head and neck squamous cell carcinoma. Semin Oncol 41: 217-234, 2014.

67. El-Rouby DH: Association of macrophages with angiogenesis in oral verrucous and squamous cell carcinomas. J Oral Pathol Med 39: 559-564, 2010

68. Liu SY, Chang LC, Pan LF, Hung YJ, Lee CH and Shieh YS: Clinicopathologic significance of tumor cell-lined vessel and microenvironment in oral squamous cell carcinoma. Oral Oncol 44: 277-285, 2008.

69. Marcus B, Arenberg D, Lee J, Kleer C, Chepeha DB, Schmalbach CE, Islam M, Paul S, Pan Q, Hanash S, et al: Prognostic factors in oral cavity and oropharyngeal squamous cell carcinoma. Cancer 101: 2779-2787, 2004.

70. Flavell R, Sanjabi S, Wrzesinski S and Licona-Limón P: The polarization of immune cells in the tumour environment by TGFbeta. Nat Rev Immunol 10: 554-567, 2010.

71. Akira S and Takeda K: Toll-like receptor signalling. Nat Rev Immunol 4: 499-511, 2004

72. Seya T, Akazawa T, Uehori J, Matsumoto M, Azuma I and Toyoshima K: Role of toll-like receptors and their adaptors in adjuvant immunotherapy for cancer. Anticancer Res 23: 4369-4376, 2003

73. Standiford TJ, Kuick R, Bhan U, Chen J, Newstead M and Keshamouni VG: TGF- $\beta$-induced IR AK-M expression in tumor-associated macrophages regulates lung tumor growth. Oncogene 30: 2475-2484, 2011

74. Schantz SP, Shillitoe EJ, Brown B and Campbell B: Natural killer cell activity and head and neck cancer: A clinical assessment. J Natl Cancer Inst 77: 869-875, 1986.

75. Schantz SP and Goepfert H: Multimodality therapy and distant metastases. The impact of natural killer cell activity. Arch Otolaryngol Head Neck Surg 113: 1207-1213, 1987.

76. Wahl SM, Wen J and Moutsopoulos NM: The kiss of death: Interrupted by NK-cell close encounters of another kind. Trends Immunol 27: 161-164, 2006.

77. Zwirner NW, Fuertes MB, Girart MV, Domaica CI and Rossi LE: Cytokine-driven regulation of NK cell functions in tumor immunity: Role of the MICA-NKG2D system. Cytokine Growth Factor Rev 18: 159-170, 2007.

78. Klöss S, Chambron N, Gardlowski T, Weil S, Koch J, Esser R, Pogge von Strandmann E, Morgan MA, Arseniev L, Seitz O and Köhl U: Cetuximab reconstitutes pro-inflammatory cytokine secretions and tumor-infiltrating capabilities of sMICA-inhibited NK cells in HNSCC tumor spheroids. Front Immunol 6: 543, 2015.

79. Ghiringhelli F, Menard C, Martin F and Zitvogel L: The role of regulatory T cells in the control of natural killer cells: Relevance during tumor progression. Immunol Rev 214: 229-238, 2006. 
80. Buessow SC, Paul RD and Lopez DM: Influence of mammary tumor progression on phenotype and function of spleen and in situ lymphocytes in mice. J Natl Cancer Inst 73: 249-255, 1984.

81. Chen WC, Lai CH, Chuang HC, Lin PY and Chen MF: Inflammation-induced myeloid-derived suppressor cells associated with squamous cell carcinoma of the head and neck. Head Neck 39: 347-355, 2017.

82. Mao L, Deng WW, Yu GT, Bu LL, Liu JF, Ma SR, Wu L, Kulkarni AB, Zhang WF and Sun ZJ: Inhibition of SRC family kinases reduces myeloid-derived suppressor cells in head and neck cancer. Int J Cancer 140: 1173-1185, 2017.

83. Pyzer AR, Cole L, Rosenblatt J and Avigan DE: Myeloid-derived suppressor cells as effectors of immune suppression in cancer. Int J Cancer 139: 1915-1926, 2016.

84. Russell SM, Lechner MG, Gong L, Megiel C, Liebertz DJ, Masood R, Correa AJ, Han J, Puri RK, Sinha UK, et al: USC-HN2, a new model cell line for recurrent oral cavity squamous cell carcinoma with immunosuppressive characteristics. Oral Oncol 47: 810-817, 2011.

85. Filipazzi P, Huber V and Rivoltini L: Phenotype, function and clinical implications of myeloid-derived suppressor cells in cancer patients. Cancer Immunol Immunother 61: 255-263, 2012.

86. Tu E, Chia PZ and Chen W: TGF $\beta$ in T cell biology and tumor immunity: Angel or devil? Cytokine Growth Factor Rev 25: 423-435, 2014

87. Wolfraim LA, Walz TM, James Z, Fernandez T and Letterio JJ: p21Cip1 and p27Kip1 act in synergy to alter the sensitivity of naive T cells to TGF-beta-mediated G1 arrest through modulation of IL-2 responsiveness. J Immunol 173: 3093-3102, 2004.

88. Tone Y, Furuuchi K, Kojima Y, Tykocinski ML, Greene MI and Tone M: Smad3 and NFAT cooperate to induce Foxp3 expression through its enhancer. Nat Immunol 9: 194-202, 2008.

89. Ivanov II, McKenzie BS, Zhou L, Tadokoro CE, Lepelley A, Lafaille JJ, Cua DJ and Littman DR: The orphan nuclear receptor RORgammat directs the differentiation program of proinflammatory IL-17 ${ }^{+} \mathrm{T}$ helper cells. Cell 126: 1121-1133, 2006.

90. Schaefer C, Kim GG, Albers A, Hoermann K, Myers EN and Whiteside TL: Characteristics of CD4+CD25+ regulatory $\mathrm{T}$ cells in the peripheral circulation of patients with head and neck cancer. Br J Cancer 92: 913-920, 2005.

91. Boucek J, Mrkvan T, Chovanec M, Kuchar M, Betka J, Boucek V, Hladikova M, Betka J, Eckschlager T and Rihova B: Regulatory $T$ cells and their prognostic value for patients with squamous cell carcinoma of the head and neck. J Cell Mol Med 14: 426-433, 2010

92. Strauss L, Bergmann C, Szczepanski M, Gooding W, Johnson JT and Whiteside TL: A unique subset of CD4+CD25highFoxp3+ $\mathrm{T}$ cells secreting interleukin-10 and transforming growth factor-beta1 mediates suppression in the tumor microenvironment. Clin Cancer Res 13: 4345-4354, 2007.

93. Bergmann C, Strauss L, Wang Y, Szczepanski MJ, Lang S, Johnson JT and Whiteside TL: T regulatory type 1 cells in squamous cell carcinoma of the head and neck: Mechanisms of suppression and expansion in advanced disease. Clin Cancer Res 14: 3706-3715, 2008.
94. Li C, Zhao Y, Zhang W and Zhang W: Increased prevalence of $\mathrm{T}(\mathrm{H}) 17$ cells in the peripheral blood of patients with head and neck squamous cell carcinoma. Oral Surg Oral Med Oral Pathol Oral Radiol Endod 112: 81-89, 2011.

95. Stockinger B, Veldhoen M and Martin B: Th17 T cells: Linking innate and adaptive immunity. Semin Immunol 19: 353-361, 2007.

96. Laad A, Kode J, Chavan S, Rao R, Fakih AR and Chiplunkar S: Limiting dilution analysis of proliferating and cytotoxic lymphocytes in the peripheral blood and tumours of oral cancer patients. Eur J Cancer B Oral Oncol 32B: 337-342, 1996.

97. Sweeny L, Liu Z, Lancaster W, Hart J, Hartman YE and Rosenthal EL: Inhibition of fibroblasts reduced head and neck cancer growth by targeting fibroblast growth factor receptor. Laryngoscope 122: 1539-1544, 2012

98. Wheeler SE, Shi H, Lin F, Dasari S, Bednash J, Thorne S, Watkins S, Joshi R and Thomas SM: Enhancement of head and neck squamous cell carcinoma proliferation, invasion, and metastasis by tumor-associated fibroblasts in preclinical models. Head Neck 36: 385-392, 2014

99. Lim KP, Cirillo N, Hassona Y, Wei W, Thurlow JK, Cheong SC, Pitiyage G, Parkinson EK and Prime SS: Fibroblast gene expression profile reflects the stage of tumour progression in oral squamous cell carcinoma. J Pathol 223: 459-469, 2011.

100. Takahashi H, Sakakura K, Kawabata-Iwakawa R, Rokudai S, Toyoda M,Nishiyama M and Chikamatsu K: Immunosuppressive activity of cancer-associated fibroblasts in head and neck squamous cell carcinoma. Cancer Immunol Immunother 64: 1407-1417, 2015

101. Rosenthal E, McCrory A, Talbert M, Young G, Murphy-Ullrich J and Gladson C: Elevated expression of TGF-betal in head and neck cancer-associated fibroblasts. Mol Carcinog 40: 116-121, 2004.

102. Xu BJ, Yan W, Jovanovic B, An AQ, Cheng N, Aakre ME, Yi Y, Eng J, Link AJ and Moses HL: Quantitative analysis of the secretome of TGF-beta signaling-deficient mammary fibroblasts. Proteomics 10: 2458-2470, 2010

103. Meng W, Xia Q, Wu L, Chen S, He X, Zhang L, Gao Q and Zhou H: Downregulation of TGF-beta receptor types II and III in oral squamous cell carcinoma and oral carcinoma-associated fibroblasts. BMC Cancer 11: 88, 2011

104. Bhowmick NA, Chytil A, Plieth D, Gorska AE, Dumont N, Shappell S, Washington MK, Neilson EG and Moses HL: TGF-beta signaling in fibroblasts modulates the oncogenic potential of adjacent epithelia. Science 303: 848-851, 2004.

105. Nema R, Vishwakarma S, Agarwal R, Panday RK and Kumar A: Emerging role of sphingosine-1-phosphate signaling in head and neck squamous cell carcinoma. Onco Targets Ther 9: 3269-3280, 2016. 